\title{
A avaliação educacional como tecnologia de controle no capitalismo neoliberal
}

\author{
Thiago Mota Fontenele Silva* \\ Sylvio Gadelha Costa**
}

\section{Resumo}

O presente artigo trata da avaliação educacional como tecnologia de controle no capitalismo neoliberal. Compõe-se basicamente de três partes, das quais a primeira se ocupa em resgatar alguns elementos relativos à genealogia das disciplinas, tal como realizada por Foucault no curso A sociedade punitiva (2013) e, posteriormente, em Vigiar e punir (1991). Dentre esses elementos, são priorizados o exame, o papel do exercício e das instâncias julgadoras, bem como o tipo de individualização característico das sociedades disciplinares, articulando-os, dentro do possível, à educação. A segunda seção, por sua vez, inicia fazendo um breve retrospecto histórico do processo de empresariamento da sociedade, em geral, e da educação, em particular; em seguida, delineia o desenvolvimento de um novo espírito do e para o capitalismo, mapeando algumas de suas principais características; e articula-o, por fim, ao advento das sociedades de controle, conforme o diagnóstico de Deleuze (1992). Na terceira seção, retornamos ao tema da avaliação e do exame, desta vez, no contexto da sociedade de controle, a fim de explorar suas conexões com as novas tecnologias de governo, lançando mão, para tanto, dos aportes teóricos introduzidos pelo sociólogo Luc Boltanski (2013) no sentido da ativação da resistência aos procedimentos educacionais de subjetivação.

Palavras-chave: Avaliação da Aprendizagem. Tecnologia Educacional. Neoliberalismo.

\footnotetext{
* Mestre e Doutorando em Filosofia pela Universidade Federal do Ceará (UFC). Professor da Faculdade Metropolitana da Grande Fortaleza (FAMETRO).

** Doutor em Educação pela Universidade Federal do Ceará (UFC). Professor do Departamento de Fundamentos de Educação e do Programa de Pós-Graduação em Educação Brasileira na Universidade Federal do Ceará (UFC).
} 


\section{Introdução: em torno do duplo imperativo da avaliação e do controle}

Até mesmo aqueles indivíduos jovens que têm a sorte de se inserirem de um modo ou de outro, e sem muita demora, no mundo produtivo, provavelmente em bem pouco tempo terão de se familiarizar e de lidar com algo que, de algumas décadas para cá, percorre esse universo de uma ponta a outra, constituindo parte significativa de seu modus operandi, perfazendo um de seus principais mecanismos de exercício e de sua lógica de funcionamento, a tal ponto que, em princípio, aparentemente, não podem nem desconhecê-lo nem tampouco recusar-se sem mais a se submeterem a ele, pelo menos se quiserem continuar minimamente incluídos nesse mundo produtivo, ou de alimentarem planos de virem a sê-lo. De que estamos falando? Trata-se, aqui, sob as injunções do mundo corporativo ou do universo empresarial, da construção de um estado de coisas, de uma espécie de ambiência ou atmosfera (que extrapola consideravelmente o âmbito privado, estendendo-se a todos os demais segmentos e organizações sociais, inclusive públicos), nos quais foi se impondo, de forma gradativa e generalizada, o duplo imperativo da avaliação e do controle, tanto de atividades ordinárias quanto da aprendizagem e do desempenho, para o que se foi mobilizando simultaneamente toda uma miríade de novas estratégias, táticas, mecanismos, práticas, procedimentos, técnicas e instrumentos. Mas, não só! Há que se acrescentar ainda o elemento propriamente problemático aí implicado, o qual remete ao fato de que, como assinala o sociólogo francês Luc Boltanski (2013), em tal mundo, em tal estado de coisas, em tal atmosfera ou ambiência, "onde cada um está permanentemente sob a ameaça do teste e é, por sua vez, incitado a pôr os outros sob teste, para lhes recompensar, lhes selecionar ou lhes eliminar, a vida social se torna simplesmente inviável e, às vezes, infernal." Tendo isso em conta, atendo-nos à realidade das sociedades contemporâneas que funcionam, em maior ou menor medida, sob a égide de um novo tipo de capitalismo - transnacional, financeiro-especulativo, conexionista e imaterial -, é desse duplo imperativo da avaliação e do controle, bem como de seus consideráveis e deletérios efeitos na vida social, particularmente no que respeita ao campo educacional, que pretendemos nos ocupar neste breve ensaio. 


\section{Foucault e a genealogia das disciplinas: a individualização disciplinar e o exame ininterrupto}

Convém, de início, que situemos historicamente o fenômeno que serve de objeto à nossa problematização. Pretendemos posicioná-lo no contexto, localizado aproximadamente no terço final do século XX, do que alguns consideram uma transição, ou uma passagem, ao passo que outros consideram uma complementação, um acoplamento, ou mesmo um agenciamento, entre, de um lado, uma forma de exercício do poder característica das sociedades disciplinares estudadas por Michel Foucault, e, de outro, uma nova e distinta forma de exercício do poder, correspondente àquelas sociedades designadas por Gilles Deleuze (1992) como sociedades de controle. Nesta primeira seção de nosso ensaio, limitar-nos-emos, no entanto, a um diálogo com algumas formulações feitas pelo Foucault genealogista do poder, sobretudo, em Vigiar e punir (1991), deixando a exploração de formulações de Deleuze acerca das sociedades de controle para a segunda e terceira seções.

Dada a ampla divulgação do que constitui para Foucault o poder e a ordem disciplinares, seus dispositivos, bem como os processos de normalização e medicalização sociais que lhes são correlativos, não nos demoraremos na caracterização das sociedades disciplinares, a não ser para delas reter alguns poucos elementos concernentes: a) ao agenciamento dos corpos ao/no tempo e ao/no espaço; b) ao exercício e; c) ao exame (avaliação e controle de atividades, aprendizagens e condutas). Tais elementos, de certa forma, ainda perduram em nossos dias, a despeito das diferenças e descontinuidades observadas em relação ao advento e ao funcionamento singular dos controlatos das sociedades de controle.

Operando um primeiro recuo estratégico para que possamos posicionar e circunscrever nosso problema, valemo-nos das páginas de Vigiar e punir (1991), nas quais, atendo-se mais ou menos ao final da época clássica, Foucault se ocupa da prática do exame, concebendo-o como um dos mecanismos, ou "recursos" capitais das (então, emergentes) disciplinas para o bom adestramento dos corpos, juntamente com a vigilância hierárquica e a sanção normalizadora. Para melhor entender a importância desse mecanismo, todavia, deve-se atentar para o fato de que ele se articula estreitamente a toda uma "arte das distribuições" (a que corresponde uma individualidade de tipo celular), a todo um "controle da atividade" (a que corresponde a uma individualidade de tipo orgânica), a toda uma "organização das gêneses" (a que corresponde uma individualidade de tipo genética) e, finalmente, a toda uma "composição de forças" (a que corresponde uma individualidade de tipo combinatória). O 
adestramento dos corpos requer que os gestos e as condutas sejam agenciados de forma minuciosa, metódica, repetitiva e ostensiva, às coordenadas do tempo e do espaço, coordenadas estas cruciais à referencialização das experiências humanas e à individualização dos sujeitos. Detenhamo-nos por um momento na questão do tempo, retendo algo importante do processo de organização de gêneses temporais, acima referido. Em face de que problema imperativo deve-se conceber a necessidade estratégica de organizar tais séries? Ao se reportar à "escola de Gobelins”, que não é mais do que um exemplo do que são as disciplinas, entendidas como técnicas que servem à apropriação do tempo de existências singulares, Foucault (1991, p. 142-143) nos esclarece sobre as questões aí em jogo:

Como capitalizar o tempo dos indivíduos, acumulá-lo em cada um deles, em seus corpos, em suas forças ou capacidades, e de uma maneira que seja suscetível de utilização e de controle? Como organizar durações rentáveis? As disciplinas, que analisam o espaço, que decompõem e recompõem as atividades, devem ser também compreendidas como aparelhos para adicionar e capitalizar o tempo.

Essa adição e essa capitalização do tempo, por sua vez, são tornadas possíveis por intermédio de quatro processos, a saber: a) dividindo-se a duração em segmentos, que tanto podem ser sucessivos quanto paralelos, devendo cada um deles, em todo caso, chegar a um termo específico; b) organizando tais sequências segmentares de acordo com um esquema analítico, que segue das partes simples em direção a totalidades complexas; c) finalizando tais segmentos temporais, fixando-lhes um termo que, por sua vez, é marcado por uma prova, de modo que se assegure, ou se garanta a um só tempo, que, em primeiro lugar, o indivíduo tenha atingido o nível esperado, em segundo, a conformidade entre o que ele aprendeu e o que foi aprendido pelos seus pares e, por fim, a diferenciação entre as suas capacidades e as destes últimos; d) estabelecendo "séries de séries", conforme as características de cada indivíduo, de tal modo que, por processos de subdivisão e ramificação, seja possível determinar os níveis e as categorias em que cada um deve ser enquadrado ${ }^{1}$. Foucault (1991) identifica aí a matriz de toda uma pedagogia analítica que se formalizou e se expandiu no transcurso da Modernidade. Além disso, tendo em vista as vicissitudes da construção desse tempo linear, evolutivo, serial, cumulativo e tendente à totalização, percebemos claramente não só os fatores que lhe permitiram articular o controle temporal ao controle comportamental (do corpo, ou melhor, das condutas), mas também apontar algumas de suas ressonâncias e/ou desdobramentos, como, por exemplo, na teoria e nas práticas da administração clássica. Segundo o autor:

A colocação em "série" das atividades sucessivas permite todo um investimento da duração pelo poder: possibilidade de um controle detalhado e de uma intervenção 
pontual (de diferenciação, de correção, de castigo, de eliminação) a cada momento do tempo; possibilidade de caracterizar, portanto de utilizar os indivíduos de acordo com o nível que têm nas séries que percorrem; possibilidade de acumular o tempo e a atividade, de encontrá-los totalizados e utilizáveis num resultado último, que é a capacidade final de um indivíduo. [...] Ora, é preciso lembrar que no mesmo momento as técnicas administrativas e econômicas de controle manifestavam um tempo social de tipo serial, orientado e cumulativo, descoberta de uma evolução em termos de "progresso". As técnicas disciplinares, por sua vez, fazem emergir séries individuais: descoberta de uma evolução em termos de "gênese". Progresso das sociedades, gênese dos indivíduos, essas duas grandes descobertas do século XVIII são talvez correlatas das novas técnicas de poder e, mais precisamente, de uma nova maneira de gerir o tempo e torná-lo útil, por recorte segmentar, por seriação, por síntese e totalização. (FOCAULT, 1991, p. 144-145).

$\mathrm{Na}$ verdade, não foram apenas novos corpos o que foi produzido no e pelo processo "fabrildisciplinar"; toda uma nova espacialidade e toda uma nova temporalidade ganharam forma em meio ao desenvolvimento do capitalismo de produção (industrial) e à secularização e racionalização da sociedade, para falar com Max Weber. Tanto essa nova espacialidade quanto essa nova temporalidade devem ser ordenadas, codificadas e homogeneizadas tendo por referência o tempo da produção. A relevância dessa ideia, presente em Vigiar e punir, de uma codificação do espaço e do tempo em função do tempo da produção, pôde ser confirmada recentemente, com a publicação, na França, em 2013, do Curso A sociedade punitiva, ministrado por Foucault no Collège de France no período letivo de 1972 - 1973 (sendo tal ideia elaborada, portanto, anteriormente à publicação do livro de 1975, dedicado ao nascimento da prisão). Um exemplo disso se encontra na aula de 21/03/1973, quando Foucault (2013, p. 220, grifos nosso) analisa um caso exemplar do que eram as instituições de sequestro, isto é, o bizarro híbrido de indústria, caserna e convento de que se compunha, por volta do ano de 1840, a usina têxtil de Jujurieux, localidade da região de Ain:

Para que aí possa haver efetivamente essa fabricação do social e essa instauração de um tempo da vida que seja homogêneo ao tempo da produção, é preciso que haja, no interior dessas instituições de sequestro: em primeiro lugar, uma instância de julgamento, uma espécie de judicatura ininterrupta, que faça com que os indivíduos estejam sempre submetidos a algo como uma instância judiciária que aprecia, impõe punições ou dá recompensas. Seja o colégio, ou a usina, ou o hospital psiquiátrico, ou a prisão, sejam formas compactas de sequestro ou formas amplas, vê-se funcionar na surdina e em suplemento uma instância judiciária. [Em segundo lugar, é preciso que haja] um tipo de discursividade, pois quem diz julgamento diz vigilância, anotações, contabilidade, etc.

Em outras palavras, já no início do trabalho de construção da genealogia das disciplinas, Foucault mostra a presença generalizada de uma “instância judiciária”, de uma “judicatura 
ininterrupta", de "uma instância de julgamento" e "de vigilância", operando nos processos de disciplinamento. Ora, essa "instância", que Foucault localiza no exemplo acima, a fábrica-prisãoconvento de Jujurieux, de maneira muita crua e contundente, não lhe é, todavia, exclusiva. Com efeito, ela faz-se presente nas mais diversas instituições disciplinares (na escola, na fábrica, no hospital, na prisão etc.), encarregando-se sempre de julgar e vigiar os sujeitos e suas condutas, à semelhança do que faz o aparelho estatal judiciário, em conformidade com padrões de normalidade e critérios de utilidade definidos pelas ciências ("médico-psi”, econômicas, políticas, dentre outras). De fato, não há disciplina sem que haja vigilância, como sugere Vigiar e punir desde o título, mas também não há disciplina sem que haja uma instância de julgamento que julga de forma ininterrupta.

Insistimos nesse ponto porque o que diz Foucault nos leva a constatar que essa instância disciplinar de julgamento, de avaliação e de exame, caracteriza-se por seu aspecto ininterrupto, contínuo, permanente. Em suma, permanência: do julgamento, do exame, da avaliação. Mas, para quê? A finalidade básica - ao menos é o que se pode depreender de passagens de Vigiar e punir (publicado originalmente em 1975), agora corroboradas pela publicação de A sociedade punitiva (curso ministrado no Collège de France no ano letivo 1972-1973, inédito até 2013), como a que aqui citamos - é instaurar um tempo de vida que seja homogêneo ao tempo de produção, é transformar todo o tempo de vida em tempo produtivo, é converter, ou “inverter", permanentemente toda forma de vida em vida útil, em sentido estritamente econômico. Assim, o nascimento das disciplinas acompanha a revolução industrial e, em seus desdobramentos, pelo menos do ponto de vista genealógico, não se pode separar, ou dissociar, de um lado, os desenvolvimentos das estratégias de poder disciplinar e, do outro, o que o marxismo chama de modo de produção capitalista. Dito de outro modo: a finalidade da disciplina e da obediência é a utilidade e o lucro. Acrescente-se a isso, por fim, que o exame se presta muito bem a essa finalidade, daí a o motivo de sua "permanência" por toda parte.

Voltaremos a abordar a questão dessa instância judiciária mais adiante. No momento, tratemos de concluir a primeira parte desse ensaio, definindo o mecanismo do exame, descrevendo algumas de suas características, situando-o em face da educação e tecendo a seu respeito, com a ajuda de Foucault, algumas considerações críticas. O que o singulariza e lhe confere importância é o fato de ele combinar funções exercidas por dois outros mecanismos disciplinares, o da vigilância hierárquica e o da sanção normalizadora. Com efeito, diz Foucault (1991, p. 164), o exame tanto constitui um controle normalizante quanto "uma vigilância que permite qualificar, classificar e punir. Estabelece sobre os indivíduos uma visibilidade através da qual eles são diferenciados e sancionados”. Em segundo lugar, o exame é imbuído de um caráter ritualístico, mediante o qual o cerimonial concernente ao exercício do 
poder disciplinar investe experiências ordinárias voltadas, por exemplo, para a aprendizagem, o adestramento, a capacitação, e ao aperfeiçoamento, em suma, à educação e à formação, tomados num sentido amplo. Em terceiro lugar, nele, a superposição de relações de saber e de relações de poder assume uma evidente visibilidade. Sua aplicação perpétua, ademais, dá ensejo, dentre outras coisas, à produção, circulação e renovação de determinados tipos de saber, de certas discursividades, servindo, portanto, para o estabelecimento de regimes de verdade.

Pode-se depreender, assim, que o vínculo de tal mecanismo com a educação e com a escola (que, então, se converte numa espécie de “aparelho de exame ininterrupto”), em particular, é a um só tempo matricial e praticamente inextricável. Vejamos como Foucault (1991, p. 166) concebe essa relação:

O exame não se contenta em sancionar um aprendizado; é um de seus fatores permanentes: sustenta-o segundo um ritual de poder constantemente renovado. $\mathrm{O}$ exame permite ao mestre, ao mesmo tempo em que transmite seu saber, levantar um campo de conhecimentos sobre seus alunos. Enquanto que a prova com que terminava um aprendizado na tradição corporativa validava uma aptidão adquirida - a "obraprima" autenticava uma transmissão de saber já feita - o exame é na escola uma verdadeira e constante troca de saberes: garante a passagem dos conhecimentos do mestre ao aluno, mas retira do aluno um saber destinado e reservado ao mestre. A escola torna-se o local de elaboração da pedagogia. E do mesmo modo como o processo do exame hospitalar permitiu a liberação epistemológica da medicina, a era da "escola examinatória" marcou o início de uma pedagogia que funciona como ciência.

Utilizando-se recorrentemente do exame, a "pedagogia científica" doravante praticada na escola moderna logra objetivar seus alunos como indivíduos produtivos e sujeitá-los à normalização disciplinar, na medida em que os expõe, também de forma recorrente, a um amplo e generalizado dispositivo de visibilidade, sendo o exame aí agenciado ao panoptismo. Isso porque o panoptismo implica que haja exame, vigilância, controle, (cabe insistir) de forma recorrente, contínua, constantemente retomada. Daí que o mecanismo do exame se adapte tão bem às práticas de formação permanente. Com essa noção, "formação permanente", não nos referimos apenas às modalidades da “educação continuada", ou da "educação permanente", mas, de modo menos técnico e mais genérico, a toda a série de práticas educacionais que virtualmente se desdobram ao longo de toda a vida de um sujeito. Em todas as práticas que se vinculam a um discurso em favor de uma educação "para a vida inteira", de um processo de formação permanente de um sujeito, isto é, em defesa de uma subjetivação ininterrupta, enfim, em todos esses processos, podemos dizer que o "exame", conforme Foucault o 
definiu, cumpre um papel decisivo e associado à estratégia panóptica de controle das condutas e de produção dos corpos e das almas dos sujeitos.

A par disso, dois outros processos, estreitamente associados entre si, consubstanciam o mecanismo do exame. Por um lado, este faz com que as individualidades entrem forçosamente num "campo documental"; por outro, servindo-se de uma série de técnicas documentárias, o exame torna cada indivíduo um "caso".

Ocupemo-nos, mesmo que de forma superficial e breve, de cada um desses processos. Quanto ao primeiro desses tópicos, o que está em pauta é o fato de a existência do indivíduo - sobretudo enquanto ele "passa" pela organização educativa -, vir a ser apreendida em suas características (particularmente, comportamentais), seus detalhes, suas vicissitudes e, num segundo momento, vir a ser remetida a um arquivo, que é propriamente o campo documentário a que se refere Foucault, de onde pode ser facilmente acessada, sempre que isso for julgado conveniente pela referida organização. Assim, procedimentos de vigilância se cruzam com procedimentos de escrita/registro (visando à identificação, assimilação e descrição dos indivíduos - professores, demais funcionários e alunos), e o resultado disso passa a constar na pasta ou no "prontuário" de cada um deles, na secretaria da escola ou no departamento de "pessoal", ou de "recursos humanos" (nos casos de organizações educacionais maiores e mais complexas). No caso dos alunos, o boletim escolar é, de longe, o documento mais importante, motivo pelo qual deve estar sempre atualizado e deve ser sempre consultado pelos professores e pela equipe psicopedagógica. Para Foucault (1991, p. 169), essa entrada da individualidade no campo documentário dá ensejo, simultaneamente, à criação de "códigos da individualidade" (o código físico da qualificação, o código médico dos sintomas e o código escolar ou militar dos comportamentos e dos desempenhos), e estes, tanto os qualitativos quanto os quantitativos, apesar de rudimentares, "marcam o momento de uma primeira 'formalização' do individual dentro das relações de poder”. Para finalizar a abordagem desse primeiro tópico, vale a pena citar um pequeno trecho em que Foucault (1991) descreve duas possibilidades correlatas abertas por esse processo de entrada da individualidade no campo documentário:

Graças a todo esse aparelho de escrita que o acompanha, o exame abre duas possibilidades correlatas: a constituição do indivíduo como objeto descritível, analisável, não contudo para reduzi-lo a traços "específicos", como fazem os naturalistas a respeito dos seres vivos; mas para mantê-lo em seus traços singulares, em sua evolução particular, em suas aptidões ou capacidades próprias, sob o controle de um saber permanente; e por outro lado a constituição de um sistema comparativo que permite a medida de fenômenos globais, a descrição de grupos, a caracterização de 
fatos coletivos, a estimativa dos desvios dos indivíduos entre si, sua distribuição numa "população". (FOUCAULT, 1991, p. 169).

Foucault sugere que a codificação da individualidade por meio da formação de arquivos pessoais, ou seja, o "arquivamento das individualidades", supõe a produção de um saber que tem de ser de caráter permanente, a fim de não apenas possibilitar o funcionamento das disciplinas, mas de otimizá-lo. Cabe notar que o caráter "permanente" desse saber é análogo àquele do exame que, como vimos, também é marcado pela constância ou pela permanência. Aliás, há uma complementaridade entre codificação permanente e exame permanente dos indivíduos, que se evidencia quando consideramos que o exame visa precisamente fornecer a matéria-prima a ser codificada, que fornece o material de que se compõem os arquivos, o input da codificação que põe os indivíduos à disposição do poder, em caráter permanente ${ }^{2}$.

Quanto ao segundo daqueles tópicos, por seu turno, o que está em questão é tanto o processo de objetivação de indivíduos na forma de casos quanto as consequências dessa objetivação. Ao tornar-se um caso, o indivíduo ao mesmo tempo se oferece como objeto de saber e constitui-se como objeto para uma tomada de decisão. Mas o que significa realmente "tornar-se um caso"? Significa, de um lado, tornar-se um indivíduo-objeto passível de identificação, descrição, mensuração, comparação (a outros objetos) - guardando sua individualidade - e, de outro, significa um indivíduo-objeto passível de ser classificado, normalizado, treinado, ou retreinado, conforme as circunstâncias assim o exijam e, no limite, caso necessário, passível de ser excluído.

Resta assinalar, por fim, que boa parte das operações capazes não só de inserirem indivíduos num campo documentário, mas também de produzirem indivíduos-objetos como casos, tal como referido acima, tiveram condições de possibilidade desde o momento em que os saberes e práticas do campo "médico-psi" e do campo psicopedagógico, passaram a orientar-se por perspectivas cientificistas, positivistas, funcionalistas e adaptacionistas de ação, sucumbindo a um operacionismo pobre, quantitativista e facilmente instrumentalizável pela lógica do poder disciplinar. E isso, por sua vez, só se tornou possível por duas razões. Em primeiro lugar, à medida que um paradigma metafísico da ciência foi gradativamente sendo substituído por um paradigma de outro tipo ${ }^{3}$, o qual, em vez de valorizar questões relativas ao significado, ao sentido e, portanto, à verdade e ao erro, pautou-se pela valorização do que era útil, operacional, instrumental, funcional, pragmático, eficaz, eficiente e inovador. Em segundo lugar, à medida que, cada vez mais orientados por esse segundo paradigma, esses saberes e práticas do campo "médico-psi” e do campo psicopedagógico se cruzam com os saberes 
e práticas oriundos da teoria da administração clássica (Taylor e Fayol), muito sensíveis às ideias e valores emanados por esse segundo paradigma.

De todo modo, no decurso do século XIX, sobretudo em sua segunda metade, algumas dentre as recém-nascidas ciências humanas, particularmente a psicologia (que nasce como ciência experimental, espécie de psicofísica das sensações) e pelo menos parte da sociologia, já emergem de certa forma "fraturadas", premidas que estavam entre, não sem ambiguidades e hesitações, tentarem compatibilizar, no âmbito de seu exercício científico, ambos os paradigmas, ou, em vez disso, renunciarem ao primeiro e adotarem o segundo deles. O caso da Psicologia, sem sombra de dúvidas, é o mais pungente e exemplar. Particularmente por volta da passagem do século XIX para o século XX, desponta a psicologia voltada à explicação das diferenças individuais e, consequentemente, ganha vulto o movimento da psicometria, com uma verdadeira explosão de testes psicológicos e psicopedagógicos, ocasião em que se inicia todo o frisson em torno das medidas e dos testes educacionais ${ }^{4}$. Essas mudanças sinalizam ao mesmo tempo com transformações observadas quanto ao modo como se davam os processos de individualização nas sociedades de soberania e nas sociedades disciplinares. Em outros termos, elas sinalizam com o que Foucault (1991, p. 171) chama de uma "troca política do eixo político da individualização". Ao passo que nas primeiras a individualização se dava, por assim dizer, pelo alto, e na descendente, nas segundas, por sua vez, a individualização se dava por baixo e numa perspectiva ascendente. Nos termos de Foucault (1991, p. 171, grifos nosso):

[...] o exame como fixação ao mesmo tempo ritual e "científica" das diferenças individuais, como aposição de cada um à sua própria singularidade (em oposição à cerimônia onde se manifestam os status, os nascimentos, os privilégios, as funções, com todo o brilho de suas marcas) indica bem a aparição de uma nova modalidade de poder em que cada um recebe como status sua própria individualidade, e onde está estatutariamente ligado aos traços, às medidas, aos desvios, às 'notas' que o caracterizam e fazem dele, de qualquer modo, um 'caso'.

\section{Empresariamento da educação, advento de um novo capitalismo e de sociedades de}

\section{controle}

Analisando a realidade da educação estadunidense, desde as primeiras décadas do século passado, até meados dos anos 1960, o sociólogo francês Christian Laval (2004) detecta tendências que apontavam para o seu crescente empresariamento. Nas primeiras décadas do século XX, esse fenômeno ainda era relativamente discreto, mas aos poucos ganhou força, intensificando-se e exprimindo-se, 
dentre outras coisas, sobretudo, pela busca de reformas e inovações modernizadoras no campo educacional. Na verdade, diz o autor (2004, p. 194), “desde o início do século 20, quer dizer, bem antes das 'inovações' dos reformadores da escola atual, a ideia de que uma escola devia ser gerenciada como uma 'empresa educativa' se tornou corrente nos Estados Unidos”. Para Laval (2004, p 190), vale a pena prestar atenção aos sentidos que acompanham os termos "modernizar" e "modernização":

Lembremos primeiro para registro que, no vocabulário das ciências sociais conquistadoras dos anos 1960, "modernizar" significava converter as sociedades ou setores da sociedade ainda tradicionais à modernidade rompendo os costumes, eliminando maneiras de ser e de fazer que repugnavam a primazia da eficácia e da racionalidade. Mas, o verbo "modernizar" significa, igualmente, em um sentido restrito, procurar um aumento da eficácia nas organizações e nas instituições para colocá-las no nível de produtividade - supondo que o termo tenha um sentido universal - das empresas privadas mais performantes.

Num primeiro registro, essa modernização se expressa por uma espécie "burocratização mecânica" das organizações sociais e educativas. No caso destas últimas, já aparece uma tendência à sua organização burocrática e gerencial. De outra parte, uma correta apreensão desse fenômeno da burocratização deve ser feita levando-se em conta não só a forma como ela, em primeiro lugar, se encaixa no processo mais amplo de empresariamento da educação, potencializando-o, mas também, em segundo lugar, considerando-se, ao contrário, o fato de ela poder vir a converter-se em obstáculo à sua consecução. Assim, por um lado, a burocratização torna mais fácil expandir eficazmente a racionalização, padronização, normalização e homogeneização de procedimentos e ações; por outro, contudo, devido justamente ao seu caráter uniforme, ao seu apego a restrições minuciosas, à mentalidade de caserna que a caracteriza, bem como às mesquinharias cotidianas concernentes às ações dos pequenos chefes (coordenadores, supervisores etc.) e das secretarias, a burocracia pode vir a terminar travando fluxos, podando a criatividade e a iniciativa, e dificultando, portanto, o resgate de ganhos de produtividade suficientes, tais como almejados pelo mercado.

A par disso, não se deve esquecer, ademais, que, por volta dos anos 1930 e 1940, época em que floresce a indústria cultural nos EUA, emerge também uma nova classe média nesse país, a dos White Collars (os de "colarinhos brancos"), conforme a designação do sociólogo Charles Wright Mills (1969). Composta eminentemente por uma massa de funcionários ou trabalhadores de escritório que compunham os quadros das grandes corporações privadas, comerciais e/ou industriais, tal classe possuía como duas de suas principais características, de um lado, o acesso ao consumo e o gozo obtido através deste, e, de outro a tendência em se identificar com o "espírito" daquelas, isto é, com o estilo de 
vida, os valores e princípios defendidos por essas grandes empresas, e delas emanados. Em decorrência, essa nova classe passou a cultivar, como desejável e como algo que poderia lhe conferir status e segurança, o ideal de integrar-se profissionalmente às mesmas, mantendo com elas uma relação duradoura, expressa, por exemplo, pelo sonho de nelas realizar toda uma carreira ascendente, garantidora, em princípio, de estabilidade financeira, conforto material, sucesso, prestígio, reconhecimento etc. Tal relação transferencial, para falar com os psicanalistas, contudo, tem lá seu preço, e, segundo José Carlos Garcia Durand (1970, p. 163), este não escapa à fina análise do livro de Mills, que traz a seguinte denúncia:

O desencantamento decorrente da burocratização que permeia todas as esferas da vida social contemporânea, e a vivência insossa do indivíduo submetido à rotina das poderosas instituições que controlam o destino individual, que sufocam as potencialidades criativas, e que, pela concentração econômica, solapam a capacidade inovadora e as possibilidades de êxito empresarial do pequeno proprietário.

O fardo desse desencanto, o qual envolve, conforme dito acima, a sensação de se viver uma vida insípida, previsível, submissa ao status quo, sem viço, sem cor, sem brilho, presa a rotinas e a um cotidiano burocrático, avesso à diferença, à criatividade, ao que é da ordem do contingente, da aventura, do jogo e da experimentação, chega mesmo a minar a imagem e o espírito desse capitalismo de produção, fato que tende a se agravar consideravelmente com toda uma série de acontecimentos posteriores que irão tumultuar a sociedade, fazendo da década de 1960, uma década intempestiva, regida pelo signo das revoluções. Para Luc Boltanski e Ève Chiapello (2009), é justo no período que se estende aproximadamente do final da década de 1960 à primeira metade da década de 1970, que, por força desse desgaste, assim como por força de uma dupla crítica, a um só tempo social e estética, a qual só tende a amplificá-lo, que se evidencia a necessidade de o capitalismo erigir para si e para toda a sociedade uma nova justificativa à sua existência. Essa justificativa coincide, para esses autores, com a construção de um novo espírito do/para o capitalismo.

Tal construção, por sua vez, é solidária a outros acontecimentos e processos. Em primeiro lugar, ela ressoa de perto com a radicalização daquele processo de empresariamento (da sociedade e da educação) a que nos referimos anteriormente. Em segundo lugar, ela coincide mais ou menos com o advento de uma nova arte de governar, neoliberal, particularmente tal como desenvolvida nos EUA pelos economistas concentrados na Escola de Chicago, sob a liderança de Milton Friedman (1988). Em terceiro lugar, a construção desse novo espírito do/para o capitalismo implica toda uma despadronização da ordem até então vigente no mundo do trabalho, tecida a duras penas durante 
décadas, sob a inspiração do New Deal de Roosevelt, da filosofia socioeconômica de John Maynard Keynes (1996), sob os auspícios do Welfare State e, ainda, em meio a inúmeras lutas e tensas negociações entre os representantes classistas do capital e do trabalho.

Esse desmanchamento de tudo o que regulamentava o mundo da produção, por seu turno, é solidário à progressiva instauração e disseminação de um sentimento de insegurança social; consequentemente, afina-se também a um processo de fragilização dos vínculos sociais (de onde, no mais das vezes, deriva uma tendência à militarização da segurança pública); e, por fim, a uma inequívoca pauperização e exclusão de milhões de vidas em nossa contemporaneidade, particularmente daquelas vidas que compõem os contingentes de pobres que vivem na periferia das grandes cidades, as populações camponesas e/ou operárias de países subdesenvolvidos, para não falar dos milhares de migrantes desterritorializados que erram sem destino seguro, tangidos pela fome, pela miséria, por perseguições étnicas, conflitos bélicos e pelo fanatismo religioso. Por outro lado, entretanto, essa fragilização dos laços de sociabilidade também atinge um contingente significativo de indivíduos ainda não totalmente excluídos, mas vivendo cada vez mais, por assim dizer, sobre o fio da navalha, por se encontrarem à beira de sê-lo. O jornalista e ativista inglês Guy Standing (2013), por exemplo, chega a falar da possível emergência em nosso presente do que seria uma nova classe social, a qual ele designa por precariado.

A despadronização do mundo do trabalho se radicaliza com o processo de globalização, apresentando-se, por seu turno, através da flexibilização, da terceirização e do leasing, dentre outros. Para finalizar, ela acompanha o advento das sociedades de controle, conforme as designa Gilles Deleuze (1992), sociedades animadas por novas modalidades de dominação, avaliação, exame, governo, condução, condicionamento e modulação de condutas e subjetividades; sociedades, além disso, em que a informação se revela como crucial e estratégica, sendo agenciada a uma lógica da comunicação, do espetáculo e do entretenimento, a um capitalismo cognitivo.

Com base, em primeiro lugar, nas problematizações feitas por Foucault em Nascimento da biopolítica (2014) sobre a governamentalidade neoliberal e, secundariamente, com base em outras análises do novo capitalismo, do neoliberalismo e/ou da arte de governar neoliberal ${ }^{5}$, dentre outros temas afins, acreditamos que o empresariamento da sociedade e da educação tem como principais características as seguintes:

a) a disseminação da "forma-empresa" por todo o tecido social; 
b) a disseminação da concorrência como princípio formalizador das relações de trabalho e de sociabilidade;

c) a generalização de práticas de ranking, classificação e triagem, em que o objetivo de todos é o mesmo, obter a melhor posição possível;

d) a invenção da teoria do capital humano (capital intelectual), mediante a qual custos/despesas são convertidos em investimentos;

e) a necessidade das pessoas de, uma vez transformadas em "indivíduos microempresa", terem de produzir, acumular e aperfeiçoar seus respectivos capitais humanos, de modo a participarem com melhores chances na acirrada competição que vigora no mercado por empregos e oportunidades, concorrência esta que determinará em grande medida sua inclusão ou exclusão social (motivo pelo qual a educação, entendida basicamente como investimento, passa a ser extremamente valorizada por elas);

f) a disseminação de uma cultura do empreendedorismo e, consequentemente, o desenvolvimento de toda uma nova expertise característica do campo do management;

g) a disseminação de uma "cultura da aferição", isto é, de verificação, de exame, de avaliação, de contabilidade, de uma prestação de contas forçada, "transparente" e recorrente, em suma, o que os políticos e homens de negócios estadunidenses designam por accountability;

h) a desterritorialização do par educação-formação, que sai dos muros da escola para se reterritorializar em qualquer outra organização social, doravante convertida à forma-empresa, senão efetivamente nas corporações comerciais e financeiras, a exemplo das universidades corporativas;

i) processo através do qual as empresas e corporações privadas pretendem transmutar seu estatuto, deixando de serem apenas organizações sociais e acalentando o objetivo de virem a se converter em verdadeiras instituições sociais, assumindo, portanto, um significativo poder normatizador e normalizador (a título de ilustração, é mediante esse processo que as grandes empresas, ou corporações, passam a ter um misto de alma e de identidade, ou um "gás", como disse Deleuze (1992), encarnando estilos de vida, valores, princípios, enfim, formas de ser e de estar no mundo, com os quais as pessoas tendem, ou melhor, são coagidas, a se identificar).

Nesse contexto, constituindo outra das facetas da radicalização desse processo de empresariamento da educação, a organização gerencial "da escola" é turbinada, a ponto de 
praticamente se poder identificar e, assim, submeter, a escola à empresa, tal como se depreende das seguintes palavras de Christian Laval (2004, p. 191-192):

Ora, o que está em jogo, especialmente na reorganização gerencial da escola, não é tanto o desaparecimento da burocracia, como é muitas vezes afirmado, quanto uma nova etapa no controle do poder de gestão, o qual deve penetrar mais na definição dos conteúdos e, até, no coração das relações pedagógicas. Os discursos atuais sobre a necessidade de uma "cultura da avaliação" na escola ou a aplicação do cálculo econômico ou de problemáticas contábeis na esfera educativa, o testemunham. A eficácia administrativa é erigida como norma suprema até o ponto em que a ação pedagógica propriamente dita é considerada como passível de avaliação como uma produção de "valor agregado". Um verdadeiro culto da eficácia e da performance se instaura, o qual dá lugar à marcação e à calibragem das "boas práticas" inovadoras que deverão ser transferidas e estendidas a todas as unidades de ensino. Tudo é visto no novo discurso de modernização sob o ângulo da técnica. As dimensões políticas que implicam em conflitos de interesse, de valores e ideais, são esvaziadas. A escola é intimada a ser "competitiva". Ela deve se adaptar ao desejo do usuário, segundo um procedimento de "serviço-cliente".

Como, então, no âmbito das sociedades de controle, podemos pensar as práticas de avaliação e exame, e como articulá-las a outros processos que lhes são correlatos? É disso que tratará a terceira e última seção de nosso ensaio.

\section{O exame e a avaliação nas sociedades de controle: examinar e avaliar, em meio à concorrência, ao empreendedorismo, ao imperativo de uma educação permanente e a uma cultura da aferição (accountability)}

Há pouco, insistíamos no fato de que, em nossa sociedade, toda a série das práticas disciplinares que constituem os exames e as avaliações vem sendo desempenhada em caráter ininterrupto, ou permanente, conforme explicitado pela análise genealógica, tal como Foucault a executa em Vigiar $e$ punir e em trabalhos preparatórios a este, como é o caso de A sociedade punitiva. De maneira condensada, podemos afirmar, com base em Foucault (1991, 2013), que o panoptismo implica que haja exame, vigilância, controle, de modo permanente, pois é, dentre outras coisas, devido à sua "permanência" que o exame consegue disponibilizar os corpos e as almas para o uso do poder, de maneira igualmente permanente. Entendemos, ainda, que esse tipo de diagnóstico não é de forma alguma datado, nem se restringe a uma época que é anterior à nossa. Pelo contrário, esse diagnóstico pode ser e tem sido prolongado contemporaneamente, através do emprego de ferramentais conceituais 
genealógicas, por exemplo, em pesquisas que encontram seus objetos brutos precisamente no campo educacional e, em particular, na escola, como faz Christian Laval (2004), mas também além dela.

É interessante notar que Deleuze (1992) também se detém no aspecto permanente dos procedimentos de exame e avaliação que operam nas práticas de subjetivação com fins educacionais, evocando-o de maneira muito particular, por intermédio da noção de formação permanente. Convém esclarecer o sentido que ligamos a essa noção no presente contexto, que não é outro sentido senão aquele que Deleuze (1992) exprime ao conceber a formação permanente, de modo geral, como a série das práticas educacionais que são suscetíveis de se prologar por todo o tempo de vida de um sujeito. Nesses termos, podemos falar, a rigor, de uma série de técnicas, toda uma tecnologia, que se produz em virtude de um discurso que propõe uma "educação para a vida inteira", ou seja, um discurso que sustenta, teoricamente, a implementação, a consolidação e a expansão de processos de formação permanente de sujeitos. Deparamo-nos aqui com um ambicioso dispositivo de subjetivação que funciona de modo constante, no qual o "exame", precisamente na acepção que Foucault (1991) atribuiu a esse termo, ou seja, em função de seu caráter permanente, vem exercer um papel estratégico inteiramente crucial, bem como os outros procedimentos "examinatórios" que a ele se agenciam como a "codificação" (arquivamento) e a redução das individualidades a "casos".

Vejamos, portanto, ainda que brevemente, algumas especificidades da concepção de exame e avaliação que Deleuze (1992) formula no Post-scriptum sobre as sociedades de controle. Em um momento chave desse texto, ao enfocar a relação entre a escola e a formação permanente, o autor (1992, p. 221, grifo do autor) toca especificamente na questão do exame: “O princípio modulador do "salário por mérito" tenta a própria Educação nacional: com efeito, assim como a empresa substitui a fábrica, a formação permanente tende a substituir a escola, e o controle contínuo substitui o exame. Este é o meio mais garantido de entregar a escola à empresa".

Deleuze (1992) opõe a descontinuidade do exame à continuidade do controle. O exame seria pontual, feito caso a caso, por certo, retomado várias vezes, mas também encerrado várias vezes. Na temporalidade da escola, por exemplo, algo ainda fica "fora" do exame, ainda existe "vida" aquém e além dos momentos de avaliação, inclusive para aqueles que ficam para a "recuperação"; ainda resta, de uma maneira ou de outra, o tempo indisciplinado fora da escola, ainda há as férias. Isso significa que, embora esteja sendo sempre reiniciado, o que gera a sensação de sua permanência - de algum modo, vive-se em função do exame, antes, durante ou depois dele (o fim de um exame já antecipa a necessidade de nos prepararmos para o próximo) -, o exame, conforme entende Deleuze, interrompese. Talvez, uma das possíveis novidades que se apresentam com o advento das sociedades de controle 
seja a cessação dessas interrupções pontuais próprias ao exame, dando lugar, doravante, às avaliações contínuas, as quais já não se submetem tão somente ao regime educacional característico da escola moderna (interrupções pontuais), mas, em vez disso, àquele que Deleuze designa como o regime educacional da formação permanente. Ao contrário do primeiro, o funcionamento deste não se limita ao interior dos "muros da escola" - assim como toda instituição disciplinar, prisão, hospital, fábrica, toda escola precisa ter seus "muros". São precisamente esses "muros" institucionais que a formação permanente vem atravessar e extravasar, sem, no entanto, destruí-los; ela os dota de uma porosidade e uma flexibilidade que se provam, ao cabo, essenciais à sua sobrevivência e/ou à permanência das disciplinas em meio às sociedades de controle. Nesse sentido, o exame permanente e a avaliação contínua invadem e colonizam o tempo livre, a fim de transformar todo tempo de vida em tempo útil.

O trecho do Post-scriptum citado acima (DELEUZE, 1992, p. 221) se reporta a uma tendência à substituição do exame pela avaliação contínua. O uso desse termo não é incidental, mas coerente com a tônica dominante do texto, da qual Deleuze (1992, p. 220, grifo original) oferece uma formulação sintética logo de saída: "São as sociedades de controle que estão substituindo as sociedades disciplinares". Cremos que essa "substituição" não deve ser entendida no sentido de um processo por meio do qual o advento do "novo" vem implicar a extinção do "velho". Essa "substituição" se apresenta como resultado, ou como efeito de uma extensão, de uma ampliação ou, ainda, de um acoplamento, algo, enfim, muito mais da ordem de uma complementação do que de uma eliminação. Falaríamos, assim, de um acoplamento da lógica das sociedades de controle à lógica das sociedades disciplinares, o que de fato produz uma nova sociedade, isto é, uma sociedade que não é mais apenas disciplinar, uma sociedade de controle, que, não obstante apresentar-se como diferente, permanece ainda, de certa forma, disciplinar.

Tendo isso em vista, retenhamos o que nos parece mais relevante no que concerne ao exame e à avaliação, segundo Deleuze (1992). Ainda no Post-scriptum, escreve este autor: "O que conta é que estamos no início de alguma coisa. [...] No regime das escolas: as formas de controle contínuo, avaliação contínua, e ação da formação permanente sobre a escola" (DELEUZE, 1992, p. 225). Nesses termos, o controle e a avaliação contínuos não "substituem” o exame disciplinar porque este já não precisa ser praticado de forma pontual e descontínua, mas pode se tornar contínuo, ou permanente, como se depreende de certas análises que Foucault $(1991,2013)$ dedica à questão do exame, conforme expusemos na seção anterior. Com efeito, a avaliação contínua e o exame interpenetram-se, de modo a serem ambos reelaborados e potencializados, de modo a tornarem-se exame-avaliação permanente, isto 
é, um procedimento que não deixa de ser disciplinar, embora passe a cumprir uma função específica de controle, constituindo assim um instrumento a um só tempo de disciplinamento e de governamento.

A potência desse grande escrito menor que é o Post-scriptum sobre as sociedades de controle de modo algum esgota-se por aí. No final do texto, referindo-se por uma última vez às práticas de formação permanente, Deleuze (1992, p. 226) diz algo que pode ser muito útil em se tratando da resistência tanto ao controle quanto à disciplina implicados às práticas de exame: "Muitos jovens pedem estranhamente para serem 'motivados', e solicitam novos estágios e formação permanente; cabe a eles descobrir a que estão sendo levados a servir, assim como seus antecessores descobriram, não sem dor, a finalidade das disciplinas".

Com suporte na ressalva que fizemos acerca do exame, ou seja, de que este não foi substituído, mas sim incorporado a uma prática avaliativa mais ampla e absorvido pelo regime de uma formação permanente, defendemos tanto que o exame se tornou contínuo quanto que essa formação permanente penetrou e modificou sensivelmente o funcionamento da escola moderna, agenciando-se e/ou somandose a este, mas isso sem que, todavia, viesse a extingui-lo por completo, ou, ao menos, a uma forma de avaliação que veio a se acoplar ao exame.

Assim, o exame se tornou contínuo, sendo absorvido pelo regime da formação permanente que, em verdade, absorveu todo o regime da escola, ou se somou a ela, sem no entanto extingui-la. É nesse sentido que corroboramos o que Deleuze diz acima, arriscando um tom mais enfático: o exame permanente, assim como a avaliação contínua, cumpre "a finalidade das disciplinas". Acrescentamos a isso que ambos também cumprem, na medida em que se agenciam aos controlatos, uma finalidade eminentemente biopolítica, a qual consiste tanto em produzir vida quanto em "fazer viver" e fazer uma "gestão do vivo". É aí que vem o interesse particular desse trecho de Deleuze para as experiências de resistência. Pois podemos dizer que essa "descoberta", seja ela voluntária ou involuntária, de que se está servindo a uma finalidade externa quando se está convicto de que se está livre e a serviço de si mesmo; essa descoberta da autonomia como autonormalização, da liberdade como autocontrole é o único acontecimento que pode levar a entender que as práticas de formação permanente, incluindo os procedimentos de avaliação contínua e exame permanente, na medida mesma em que desenvolvem suas estratégias promocionais, constituem focos de resistência, locus em que a luta não só pode como deve se concentrar. E isso não nos fornece apenas um par de coordenadas topográficas para uma cartografia que sirva de suporte a eventuais atos de resistência, ou seja, isso não nos mostra apenas a linha dura em face da qual se trataria de traçar uma tangente, mas nos mostra também um dos traços gerais que as táticas e as práticas de resistência precisam assumir: a quebra da continuidade, a 
descontinuação, a ruptura, a interrupção. No caso específico do procedimento de exame-avaliação permanente, isso é muito claro: o objetivo da resistência é interrompê-los, bloqueá-los ou, na pior das hipóteses, atenuá-los. Finalizando nossas considerações, lançamos mão de algumas ideias do sociólogo Luc Boltanski, tanto sobre práticas de exame e controle quanto acerca de possíveis resistências em face deles.

Em 2013, veio a público o impactante documentário Nosso mundo [Notre monde], dirigido por Thomas Lacoste, cineasta que interpelou mais de 35 convidados, dentre os quais filósofos, sociólogos, economistas, juristas, médicos, jornalistas e escritores, convidando-os a "fazer política, de preferência, de outra maneira”. Mais especificamente, o triplo desafio lançado à intelligentsia francesa por Lacoste, segundo esclarece em sua fala o filósofo Jean-Luc Nancy, consistia em: de início, indicar um campo de ação; em seguida, diagnosticar um problema neste campo; e, por fim, apresentar uma proposição concreta de intervenção, tendo em vista, se não eliminar esse problema, ao menos atenuar seus efeitos. Uma das intervenções mais contundentes de Nosso mundo é a do sociólogo Luc Boltanski, a qual funcionou em grande medida como gatilho para a abordagem que desenvolvemos neste texto sobre a questão da avaliação, por intermédio das tecnologias disciplinares, de gestão e de controle, na era do empresariamento generalizado das sociedades. Por essa razão, no que segue, acompanharemos de perto o percurso da fala de Boltanski (2013), intitulada Abaixo a excelência [À bas l'excellence], um verdadeiro libelo contra a ditadura da meritocracia contemporânea, cuja extensão diminuta - trata-se, com efeito, de uma fala "menor" ou "minoritária", no sentido de Deleuze - é inversamente proporcional à intensidade de seu impacto nos ouvintes. O intuito deliberado de Boltanski é desestabilizar certezas, em geral, tomadas como sólidas e consistentes, e, ao que nos consta, ele o alcança muito bem. Porém, não o faz sem nos proporcionar, em compensação, um fôlego produtivo, novo e diferente, que constitui também um tônico revigorante a todos os que se sentem indignados com aquela ditadura e com a coação típica de um regime de avaliação permanente e generalizada, aos quais buscam resistir.

A fim de discernir causas para o problema contemporâneo do desfazimento dos coletivos e ao dos danos que daí decorrem para os indivíduos, ao se verem, assim, desconectados, atomizados, individualizados - a despeito do desenvolvimento de tecnologias informacionais que lhes induzem a acreditar que estão cada vez mais próximos uns dos outros, conectados virtualmente, por via digital -, Boltanski aponta para um fator que lhe parece primordial: a disseminação do que ele designa como dispositivos de avaliação. Esses, na medida em que se prestam a expedientes de hierarquização e de 
fabricação de distinções, especialmente através da introdução de sistemas de premiação, estariam, para ele, entre os principais responsáveis pela exacerbação do individualismo e pelo acirramento da concorrência, dentro e fora do ambiente de trabalho, aspectos que, ademais, vêm conduzindo a uma corrosão do interior das pessoas e a um amesquinhamento da vida não só dos indivíduos, mas também dos grupos e coletividades.

Assim, podemos compreender a noção de dispositivos de avaliação, no sentido de Boltanski (2013), como uma série de práticas apoiadas em saberes específicos que dispõem os/dos indivíduos, ou grupos, de maneira hierárquica, visando a selecionar, de acordo com critérios quantitativos, impostos de fora, por júris de experts, os "vencedores", cuja imagem, sempre atrelada àquela do "premiador", e por ele conferida, presta-se à exibição e à ostentação pública exaustiva. Os dispositivos de avaliação exercem, portanto, uma função "biopolítica", na medida em que visam, ao mesmo tempo, a qualificação de certas formas de vida e, correlativamente, a desqualificação de outras. De um lado, trata-se de identificar, localizar e classificar segmentos individuais e/ou coletivos, descrevendo e mensurando seus atributos, a fim de definir que política de investimentos deve ser a eles aplicada, tendo em vista a elevação da quantidade de capital humano ali antevista ou estimada. Com relação a determinados segmentos, sejam eles individuais, grupais, ou populacionais, o objetivo é a capacitação profissional e o aumento dos padrões de desempenho. Nesses casos, são esses que se trata de incluir e de "fazer viver"; são eles que constituem a "vida útil". Entretanto, há outros segmentos que perdem suas identidades ao serem deslocados e desclassificados. É nesses que não se deve investir, pois todo investimento feito aí é dado, de antemão, como perdido. Esse segmento constitui a "vida inútil", isto é, a vida a ser excluída e deixada à míngua, ou ainda, as formas de vida que é melhor "deixar morrer". Entre esses segmentos, os dispositivos que Boltanski intitula como “dispositivos de avaliação" operam por meio dos procedimentos de exame permanente e de avaliação contínua, os quais se encarregam de traçar a linha de corte que separa não apenas os aprovados dos reprovados, mas os avaliáveis dos inavaliáveis.

Boltanski registra que esses dispositivos se fazem presentes quase em toda parte, como que atravessando a superfície do socius de um extremo ao outro, percorrendo diferentes espaços (educativos, sociais, culturais, administrativos, de segurança, de saúde etc.), muitas vezes contaminando uns com as lógicas dos outros - o empresariamento generalizado não é, nesse sentido, senão um exemplo dessas múltiplas contaminações. Os dispositivos de avaliação encontram suporte em certa concepção de "justiça" que eles veiculam e tratam de reproduzir. Essa é, todavia, no entender de Boltanski (2013,), uma "justiça discriminatória”, que vem substituir uma "justiça social” e que, ao 
invés de promover a igualdade por meio de políticas de compensação das desigualdades em larga escala, "seleciona e recompensa, em particular por um sistema de premiações, os melhores, os campeões, os performantes, em uma lógica que se pretende dominada pela busca da excelência”.

Encarregados da produção seletiva de vida útil, os dispositivos de avaliação são desempenhados em função de certo critério ligado aos imperativos políticos e econômicos da governabilidade e da produtividade, da obediência e da utilidade. Segundo Boltanski (2013) essas técnicas de avaliação como o exame permanente e a avaliação contínua - provêm do universo do management, do mundo empresarial. Ao se generalizarem, isto é, ao se incorporarem a um "dispositivo" que extravasa os limites da fábrica, levando a todo lugar o "espírito empreendedor" e a "forma-empresa", as técnicas de avaliação empresarial se cristalizam como um modelo de governança, ou seja, como um recurso de governamento peculiarmente eficaz, penetrante e difícil de contrariar. Para Boltanski $(2013)^{6}$, “Organizando a luta de todos contra todos, elas [essas técnicas de avaliação] tendem a destruir as formas de solidariedade e ajuda mútua por meio das quais os atores da vida social se ligam para opor uma resistência coletiva à opressão". Anárquicos, mas anticooperativos porque concorrenciais, esses métodos nos incitam a todos, das mais diversas maneiras, a atender a uma única exigência, que pode ser formulada, na linguagem do management, como o imperativo de maximizar o indicador.

Assim, a exigência, essencialmente externa, tanto por mais produtividade quanto por mais governabilidade, tanto por mais utilidade quanto por mais obediência, ocorre, no sujeito, como uma demanda interna, como desejo, que, ao mesmo tempo, o identifica e permite que ele identifique a si mesmo. O sujeito não descobre a si na oposição de seu desejo à lei; ele descobre que a lei é seu desejo. O nomos revela-se, enfim, como autonomos, e a disciplina, por sua vez, como forma de governo de si, como autonomia. A lei não é mais, assim, a antítese da liberdade, mas aquilo mesmo que a torna possível, sua condição mesma de possibilidade. Não obstante, a lei, a exigência, o critério, a norma, a despeito de profundamente interiorizados, mantêm-se ainda como externos ao sujeito. É a objetividade da norma que permite que o nomos funcione como critério objetivo nas práticas de avaliação, as quais podem evidentemente incidir sobre as condutas "autônomas" dos sujeitos. O nomos dessa autonomia avaliada (e alienada) é a norma. A autonomia não se mostra aí como ação de produzir e de dar seu desejo a si mesmo, fazer de seu desejo sua lei, isto é, como uma liberdade radical, mas, sim, como autonormalização, isto é, toda uma série de práticas por meio das quais o sujeito normaliza a si mesmo, pondo-se "na linha", em conformidade com as "exigências", dispensando doravante intervenção 
externa. E é justamente isso que acabamos de descrever, ou seja, esse processo de autonormalização, o que um número lamentavelmente importante de discursos designa com o termo "liberdade".

Boltanski (2003) vai, contudo, concluir suas considerações em tom de resistência, que é o tom em que também vamos concluir. No que concerne à produção da intervenção concreta possível, tendo em vista se não eliminar, ao menos aplacar os efeitos perversos do dispositivo de avaliação, entende o sociólogo que:

Medidas concretas devem e podem ser aplicadas para pôr fim à tirania da "excelência", no sentido em que essa qualificação é aplicada pelas instâncias de management. Elas são múltiplas. Entre as primeiras a serem postas em prática, menciona-se a supressão dos sistemas de concorrência entre as pessoas no trabalho que repousem sobre a outorga de prêmios individuais, indexados a objetivos, fixados arbitrariamente pelas hierarquias, em função de exigências burocráticas e/ou políticas. E também, mais geralmente, o abandono de procedimentos que, a pretexto de "responsabilizar" os atores da vida social, visam, de fato, a lhes culpabilizar, fazendo-lhes endossar a causa dos males que lhes oprimem. Isso, segundo uma modalidade que consiste em "culpar as vítimas", posta, há longa data, a serviço da justificação da exploração. É preciso, igualmente, dar preferência ao longo prazo sobre o curto, o que teria como efeito adiar o momento do teste. Podemos relativizar a avaliação e atenuar sua violência tomando em conta a incerteza, que é sempre o quinhão comum. (BOLTANSKI, 2003, Informação oral, grifos nosso).

Para encerrar, portanto, não é preciso mais do que enfatizar, dentre as "medidas concretas" aí enumeradas por Boltanski, aquela que nos parece constituir o encaminhamento mais imediato que poderíamos adotar, a fim de organizar ou reforçar a resistência contra os dispositivos de avaliação, a saber: ampliar os prazos e postergar o momento do exame e da avaliação. Para a resistência, trata-se, com efeito, de investir de imediato contra o "tempo da produção", tentando instaurar outra temporalidade - não apenas uma heterotopia, mas uma "heterocronia" - que possibilite que a vida seja vivida de outra forma, ou que torne possível a existência de outras formas de vida, de vidas inavaliáveis e inapreciáveis, porque vividas para além de qualquer valoração. Para tanto, necessitamos de estratégias de interrupção e de bloqueio. Trocando em miúdos, se o exame e a avaliação tendem a se tornar ininterruptos, precisamos dar um jeito de interrompêe-los. O interessante é notar que isso pode ser feito de modo muito concreto e pontual, tão pontual quanto é cada um dos "exames" e das "avaliações" a que já somos submetidos, seja como professores, seja como alunos, em caráter permanente, no seio de práticas educacionais que se quer fazer incidir, e que em boa medida já incidem, sobre todos os pontos de nossa existência. 


\section{Notas}

${ }^{1}$ Todos esses quatro processos só se tornam efetivos com o concurso do exercício, definido por Foucault (1991, p. 145-146, grifos nossos) como a "técnica pela qual se impõe aos corpos tarefas ao mesmo tempo repetitivas e diferentes, mas sempre graduadas. Dirigindo o comportamento para um estado terminal, o exercício permite uma perpétua caracterização do indivíduo seja em relação a esse termo, seja em relação aos outros indivíduos, seja em relação a um tipo de percurso. Assim, realiza, na forma da continuidade e da coerção, um crescimento, uma observação, uma qualificação".

${ }^{2}$ A pertinência desse tipo de análise, que já estava presente em 1975, em Vigiar e punir, e mesmo antes, pode ser dimensionada se tivermos em mente algo como o impasse diplomático gerado pelo escândalo de espionagem que veio a público a partir do chamado "caso Snowden". No caso, o agente especializado em segurança digital, Edward Snowden, da Agência Nacional de Segurança (National Security Agency NSA) - divisão então secreta da famosa agência de inteligência, a CIA -, que tinha acesso a uma imensa quantidade de documentos ultrassigilosos envolvendo operações de hacking realizadas a mando do governo dos EUA, resolveu divulgar amplamente essas informações, em nome, segundo ele, dos interesses dos reais mandatários do Estado norte-americano, o povo norte-americano, bem como do interesse de inúmeros outros povos e indivíduos, incluindo seus líderes oficiais, até mesmo a presidente Dilma Rousseff (GREENWALD, 2014). Sem saber, estávamos entrando onde agora sabemos bem que estamos: na era de uma ciber-vigilância permanente, na era do ciber-panóptico.

${ }^{3}$ Esse paradigma vai se esboçando aos poucos, mas talvez possamos afirmar que ele assume maior substancialidade, definição e acabamento por volta do final dos anos 1940 e começo dos anos 1950, com o advento da cibernética. Nós o nomearemos como paradigma cibernético-informacional. Particularmente depois da segunda metade dos anos 1970, por ocasião das revoluções nos campos das tecnologias da informação e da comunicação, bem como no campo das biotecnologias, para não mencionar os efeitos nele refletidos da convergência de todas essas tecnologias, esse paradigma assume novos contornos (com as neurociências, por exemplo), torna-se objeto de investimentos, é revalorizado e ganha considerável complexidade, podendo ser qualificado, conforme sugestão do Prof. Dr. Homero de Lima (2010), de paradigma cibernético-informacional de matriz molecular-digital.

${ }^{4}$ Como assinala Goulart (1995, p. 15), "enquanto a Psicologia Experimental tentava descobrir os padrões universais de realização (as uniformidades) e considerava as diferenças de resultados como 'erros' do instrumento ou da situação, a função básica da Psicometria consistia na avaliação das diferenças entre os indivíduos ou entre as reações de um mesmo indivíduo em momentos diversos".

${ }^{5}$ Klein (2004) Boltanski e Chiapello (2009); López-Ruiz (2007); Gadelha (2009); Laval (2004); Dardot e Laval (2009); Ehremberg (2010); Gaulejac (2007); Bendassoli (2009); Lazzarato (2013).

${ }^{6}$ Depoimento intitulado À bas l'excellence, concedido por Boltanski ao diretor Thomas Lacoste no documentário Notre monde. Agat Films \& Cie, La Bande Passante, Sister Productions. França, 2013. 90 min. Color.

\section{REFERÊNCIAS}

BENDASSOLI, Pedro. Os Fetiches da Gestão. Aparecida, SP: Ideias \& Letras, 2009.

BOLTANSKI, Luc. À bas l'excellence. In: NOTRE monde. Direção: Thomas Lacoste. Paris: Agat Films \& Cie, La Bande Passante, Sister Productions. 2013. 90 min. Color.

BOLTANSKI, Luc; CHIAPELLO, Ève. O novo espírito do capitalismo. São Paulo: Martins Fontes, 2009. 
DARDOT, Pierre; LAVAL, Christian. La Nouvelle Raison du Monde: essai sur la société neoliberale. Paris: La Découverte, 2009.

DELEUZE, Gilles. Post-scriptum sobre as sociedades de controle. In: DELEUZE, Gilles.

Conversações. Rio de Janeiro: Editora 34, 1992. (Coleção TRANS). p. 219-226.

DURAND, José Carlos G. Resenha bibliográfica de A Nova Classe Média (White collar), de Charles W. Mills. Revista de Administração de Empresas. São Paulo, v. 10, n. 1, p. 163-166. jan./mar. 1970. Disponível em: <http://rae.fgv.br/sites/rae.fgv.br/files/artigos/10.1590_s0034-

75901970000100010 .pdf.>. Acesso em: 30 jun. 2015.

EHREMBERG, Alain. $O$ Culto da Performance: da aventura empreendedora à depressão nervosa. Aparecida, SP: Saraiva, 2010.

FOUCAULT, Michel. Vigiar e punir: nascimento da prisão. 9. ed. Petrópolis, RJ: Vozes, 1991.

FOUCAULT, Michel. La société punitive: cours au Collège de France (1972-1973). Paris: Seui; Gallimard, 2013.

FOUCAULT, Michel. Nascimento da Biopolítica: curso no Collège de France (1979-1980). São Paulo: Martins Fontes, 2014.

FRIEDMAN, Milton. Capitalismo e liberdade. 3. ed. São Paulo: Nova cultural, 1988.

GADELHA, Sylvio. Biopolítica, governamentalidade e educação: introdução e conexões, a partir de Michel Foucault. Belo Horizonte: Autêntica, 2009.

GAULEJAC, Vincent de. Gestão como Doença Social: ideologia, poder gerencialista e fragmentação social. Aparecida, SP: Ideias \& Letras, 2007.

GOULART, Iris B. Psicologia da educação: fundamentos teóricos e aplicações à prática pedagógica. Petrópolis, RJ: Vozes, 1995.

GREENWALD, Glenn. Sem lugar para se esconder: Edward Snowden, a NSA e a espionagem do governo americano. Rio de Janeiro: Sextante, 2014.

KEYNES, John Maynard. A teoria geral do emprego, do juro e da moeda. São Paulo: Nova Cultural, 1996.

KLEIN, Naomi. Sem Logo: a tirania das marcas em um planeta vendido. Rio de Janeiro: Record, 2004.

LAVAL, Christian. A escola não é uma empresa: o neo-liberalismo em ataque ao ensino público. Londrina, PR: Planta, 2004.

LAZZARATO, Maurizio. La Fabrica del Hombre Endeudado: ensayo sobre la condición neoliberal. Buenos Aires: Amorrortu, 2013. 
LIMA, Homero Luís A. de. Do corpo-máquina ao corpo-informação: o pós-humanismo como horizonte biotecnológico. Curitiba: Honoris Causa, 2010.

LÓPEZ-RUIZ, Osvaldo. Os Executivos das Transnacionais e o Espírito do Capitalismo: capital humano e empreendedorismo como valores sociais. Rio de Janeiro: Azougue, 2007.

MILLS, Charles W. A nova classe média. Rio de Janeiro: Zahar, 1969.

STANDING, Guy. O precariado: a nova classe perigosa. Belo Horizonte: Autêntica, 2013. 


\section{Educational evaluation as control technology in neoliberal capitalism}

\begin{abstract}
This text deals with the educational evaluation as control technology in neoliberal capitalism. Basically it consists of three parts, the first of which is dedicated to a rescue of some elements from the genealogy of the disciplines, such as performed by Foucault in his lectures on The punitive society (2013), and subsequently in Discipline and punish (1991). Among these elements, we prioritize the exam, the role played by the exercise and by judicial instances, as well as the type of individualization characteristic of disciplinary societies. Furthermore, we try, whenever possible, to show how it links to educational topics. On its turn, the second section starts with a brief historical retrospect of entrepreneurship, generally, in society, and particularly in education; then, it outlines the development of a new spirit of capitalism, and draws a map some of its main features; finally, it relates the whole process to the advent of societies of control, according to Deleuze's diagnosis (1992). In the third section, we return to the topic of evaluation and examination, now within the context of the control society, to explore their connections with the new technologies of government, and we use some of the theoretical devices introduced by the sociologist Luc Boltanski (2013) to activate the resistance to the educational procedures of subjectivation.
\end{abstract}

Keywords: Learning Evaluation. Educational Technology. Neoliberalism.

Thiago Mota Fontenele Silva

E-mail: thmotafs@gmail.com

Sylvio Gadelha Costa

E-mail: sylviogadelha@uol.com.br
L'évaluation éducationnelle en tant que technologie de contrôle dans le capitalisme néolibéral

\section{Résumé}

Cet essai porte sur l'évaluation éducative comme technologie de contrôle dans le capitalisme néolibéral. Il est composé de trois parties, dont la première récupère certains éléments concernant la généalogie des disciplines, telle qu'elle a été exécutée par Foucault dans le cours La société punitive (2013) et par la suite dans Surveiller et punir (1991). Parmi ces éléments, ont été priorisés l'examen, le rôle joué par exercice et par les instances de jugement, ainsi que le type de l'individualisation caractéristique des sociétés disciplinaires, toujours en essayant de les lier, autant que possible, à l'éducation. La deuxième section, à son tour, commence pour faire une brève rétrospective historique de l'entrepreneuriat, dans la société en général et dans l'éducation en particulier; puis, on décrit la construction d'un nouvel esprit du capitalisme et certaines de ses caractéristiques principales ; et, enfin, on les relie à l'avènement des sociétés de contrôle, selon de diagnostic de Deleuze (1992). Dans la troisième section, nous revenons à la question de l'évaluation et des examens, cette fois-ci, dans le contexte de la société de contrôle, afin d'explorer leurs connexions aux nouvelles technologies du gouvernement, tout en utilisant, pour ce fin, les apports théoriques introduits par le sociologue Luc Boltanski (2013), dans le sens de l'activation de la résistance aux procédures éducatives de subjectivation.

Mots-clés: Évaluation de l'Apprentissage. Technologie Éducationnelle. Néolibéralisme.

Enviado em: 24/7/2015

Aprovado em: 10/10/2016 